\title{
DIVULGANDO A CIÊNCIA EM HISTÓRIAS EM QUADRINHOS: investigações periciais e suas relações com a Química
}

\author{
Edemar Benedetti Filho \\ Universidade Federal de São Carlos - UFSCar \\ edemarfilho@yahoo.com.br
}

Alexandre Donizeti Martins Cavagis

Universidade Federal de São Carlos - UFSCar

cavagis@ufscar.br

Luzia Pires dos Santos Benedetti

Universidade Federal de São Carlos - UFSCar

luziabenedetti@yahoo.com.br

\begin{abstract}
Resumo
O presente artigo descreve o desenvolvimento de uma história em quadrinhos (HQ), incluindo roteiro, diagramação e arte gráfica, assim como sua aplicação em uma aula de Química, para estudantes de terceiro ano do Ensino Médio. A história se baseia na investigação de um suposto crime, destacando o papel de um químico forense e a importância de seus conhecimentos em Química para elucidação do mistério. O trabalho também envolveu estudantes de licenciatura em Química, cursando estágio supervisionado, além da professora da disciplina, contribuindo assim para a formação inicial e continuada de professores. Os resultados obtidos corroboram o fato de que, quando adequadamente usadas, as HQs representam ferramentas promissoras para divulgação científica, trabalhando habilidades normalmente pouco contempladas no ensino tradicional, favorecendo assim uma melhor integração em sala de aula e auxiliando os professores a aproximar suas práxis pedagógicas de seus alunos.
\end{abstract}

Palavras-chave: Atividades lúdicas. Ensino de Ciências. Formação de Professores.

\section{DISSEMINATING SCIENCE IN COMIC BOOKS: forensic investigations and their relations with Chemistry}

\begin{abstract}
This article describes the development of a comic book, including script, text formatting and graphic art, as well as its application, in a Chemistry class. The story is based on the investigation of an alleged crime, highlighting the role of a forensic chemist as well as the importance of his Chemistry expertise to elucidate the mystery. The work also involved undergraduate students in Chemistry, in the scope of supervised practice, beyond the teacher of the discipline, thus contributing to the initial and continued formation of teachers. The results obtained corroborate the fact that, since properly used, comics represent promising tools for dissemination science, exercising skills, which are not usually contemplated in traditional teaching, thus favoring a greater integration in the classroom and helping teachers to approach the pedagogical praxis of their students.
\end{abstract}

Keywords: Playful activities, Science Education, Teacher training.

\section{DIVULGACIÓN DE LA CIENCIA EN HISTORIAS EN IMÁGENES: investigaciones expertas y sus relaciones con la química}

\section{Resumen}

Este artículo describe el desarrollo de un cómic (cómic), que incluye guiones, diagramas y artes gráficas, así como su aplicación en una clase de química para estudiantes de secundaria de tercer año.

Cidadania em Ação: Revista de Extensão e Cultura, Florianópolis (SC), v.4, n.2, jul./dez. 2019. 
La historia se basa en la investigación de un presunto delito, destacando el papel de un químico forense y la importancia de su conocimiento en química para dilucidar el misterio. El trabajo también involucró a estudiantes de pregrado en Química, asistiendo a pasantías supervisadas, además del maestro de la asignatura, contribuyendo así a la formación inicial y continua de los maestros. Los resultados corroboran el hecho de que, cuando se usan adecuadamente, los cómics representan herramientas prometedoras para la divulgación de las ciencias, habilidades de trabajo que no se consideran comúnmente en la enseñanza tradicional, lo que favorece una mejor integración en el aula y ayuda a los maestros a abordar su praxis. de sus alumnos.

Palabras clave: Actividades de juego, Enseñanza de la ciência, Formación del profesorado. 


\section{INTRODUÇÃO}

O emprego de metodologias alternativas no Ensino vem ganhando espaço no contexto escolar, visando a uma aprendizagem mais significativa, por meio de ferramentas pedagógicas que propiciem a ludicidade. Tais ferramentas contribuem para o aumento no interesse pela disciplina e, nessa perspectiva, o professor tem papel importante como mediador da aprendizagem, na busca por estratégias que ampliem os conhecimentos e melhorem a interpretação e o entendimento de conceitos científicos. Diante deste interesse dos alunos por novos conhecimentos a divulgação científica possui um papel importante.

A literatura relaciona inúmeras atividades diversificadas, que transpõem o sistema tradicional de ensino, tais como jogos (OLIVEIRA et al., 2018), músicas (SILVA; KIOURANIS, 2008), vídeos (SILVA et al., 2012; ALMEIDA et al., 2018), teatro (NETO et $a l ., 2013)$ etc., e elas possuem um papel importante para ilustrar os conhecimentos de uma maneira mais prazerosa aos alunos, e neste contexto as histórias em quadrinhos (HQs) também estão inseridas como alternativas para a divulgação científica.

HQs relacionadas à divulgação científica podem contribuir significativamente no sentido de despertar e ampliar o interesse dos alunos, pois trazem imagens coloridas, roteiros envolventes e situações do cotidiano, relacionadas em contextos pedagógicos que propiciam a inserção de conceitos de Ciência e Tecnologia aos leitores. Assim, as histórias em quadrinhos estabelecem uma comunicação lúdica com o leitor, oferecendo-lhe fácil leitura e entretenimento, por meio de linguagem simples e narrativa leve (VILLELA, 2017), sendo assim mais prazeroso que a leitura de um texto comum.

Segundo Testoni (2003), as HQs, podem apresentar categorias diferentes quanto à finalidade pedagógica, tais como representar graficamente o conteúdo, explicando o conceito inserido no enredo da história, induzindo o aluno a refletir durante as narrativas para compreender o fenômeno científico relacionado. Além disso, o emprego das HQs permite o estímulo de outras habilidades, tais como as relacionadas ao lúdico, à escrita, à linguagem, à interpretação textual, à criatividade e imaginação, podendo assim despertar e ampliar o interesse do aluno (leitor) pela Ciência.

As HQs vêm ganhando espaço no ambiente escolar (CABELLO et al., 2010; CAVALCANTE et al., 2015; FRANCISCO JÚNIOR; GAMA, 2017; IANESKO et al., 2017); sua utilização de forma lúdica pode harmonizar, no mesmo enredo, diversas áreas do conhecimento, em diferentes contextos de ensino, ambientes e idades escolares. Tal 
versatilidade educacional fez com que crescesse o interesse por essa ferramenta pedagógica no Brasil, conforme descrito nas orientações técnicas veiculadas pelos Parâmetros Curriculares Nacionais (PCN), em consonância com o estabelecido pela Lei de Diretrizes e Bases (LDB 9364/96), prevendo seu emprego nos mais variados níveis e modalidades (VERGUEIRO; RAMA, 2004).

Segundo Calazans (2004), com base em resultados científicos descrevendo a importância do emprego do uso de HQs em sala de aula, a totalidade dos alunos tem preferência pela leitura de quadrinhos (HQs) do que por qualquer outro tipo de publicação. Portanto, o grande incentivo à leitura proporcionado pelos quadrinhos seduz os alunos para uma leitura mais prazerosa e espontânea, auxiliando-os na apropriação dos conceitos de Ciências.

As HQs têm sido aplicadas cada vez mais, sobretudo nos últimos anos, para o ensino de Ciências. Percebeu-se que esse tipo de publicação ajuda muito a despertar interesse e curiosidade do público em geral para temas científicos. O próprio governo utiliza constantemente esse tipo de publicação na divulgação de assuntos de interesse público, como em campanhas de vacinação, orientações sobre descarte correto de lixo e uso adequado de recursos hídricos e energia elétrica, nas campanhas de prevenção de doenças etc. A leitura, em conjunto com as ilustrações gráficas, permite melhor compreensão do texto e fixação das informações, sendo útil à ampla maioria da população, mesmo àqueles com certa dificuldade de leitura (CABELLO et al., 2010).

Estudos demonstram que grande parcela da sociedade brasileira não possui o hábito da leitura, fato que se confirma pela preferência pelos filmes dublados em vez dos legendados (GIRON, 2012). Segundo Santos (2003), a divulgação e a alfabetização científicas são mais eficazes utilizando as histórias em quadrinhos como ferramentas de leitura, propiciando ao leitor imaginar, participar da trama descritiva, interagindo com a história, experiências que são essenciais para despertar o gosto pela leitura. Aplicar o uso de HQs no Ensino Fundamental e Médio, com textos científicos, podem representar uma estratégia pedagógica eficaz no sentido de preparar os alunos para leituras mais encorpadas, como de textos didáticos, informativos e, até mesmo, obras literárias.

O uso de HQs no processo de divulgação científica é predominantemente descrito como eficaz, contudo, pesquisas científicas relacionadas ainda são relativamente escassas, muitas vezes devido à ideia de que o emprego dos quadrinhos seria apenas para o público infantil e objeto de uso somente para a melhora na leitura (Vergueiro, 2004).

Cidadania em Ação: Revista de Extensão e Cultura, Florianópolis (SC), v.4, n.2, jul./dez. 2019. 
Por representarem um meio de comunicação de vasto consumo e com conteúdo, até os dias de hoje, majoritariamente direcionado às crianças e jovens, as HQs cedo se tornaram objeto de restrição, condenadas por muitos pais e professores no mundo inteiro (...). Pais e mestres desconfiavam das aventuras fantasiosas das páginas multicoloridas das HQs, supondo que elas poderiam afastar crianças e jovens de leituras "mais profundas", desviando-os, assim, de um amadurecimento "sadio e responsável". Daí, a entrada dos quadrinhos em sala de aula encontrou severas restrições, acabando por serem banidos, muitas vezes de forma até violenta, do ambiente escolar. Aos poucos, tais restrições foram atenuadas e extinguidas, mas não de forma tranquila, sendo na verdade resultado de uma longa e árdua jornada.(VERGUEIRO, 2004, p.8).

O receio do uso das HQs em atividades pedagógicas de Ciências no Ensino Médio e o uso restrito dessa ferramenta no Ensino Fundamental acarretaram deficiências aos professores sobre como fazer e como utilizar as HQs em sala de aula para o ensino de Ciências, especialmente nas disciplinas de Física e Química. Nessa perspectiva, é necessário que os docentes tenham subsídios que possam orientá-los na incorporação dessa ferramenta didática em sua práxis pedagógica (PIZARRO, 2009), e na sua divulgação entre os alunos.

(...) a ausência de propostas para uma metodologia que envolva quadrinhos e conteúdos científicos abre uma lacuna a ser preenchida por pesquisadores e professores que desejem se aventurar em práticas que fomentem propostas plausíveis de aproveitamento deste material para a divulgação e educação científica.(PIZARRO, 2009).

Segundo Santos et al. (2012), o principal motivo para a não utilização das HQs em sala de aula é o fato de que tal publicação não tem como origem a academia, mas editoras que visam somente a promover entretenimento, sem levar em conta conceitos e aspectos científicos corretos e destacando aquilo que é puramente empolgante aos leitores, independentemente se tem ou não fundamento científico. Como exemplo, a "visão de raios $\mathrm{X}$ do Super Homem”, com luz saindo de seus olhos ao invés de ser recebida por eles.

\section{METODOLOGIA}

A história em quadrinhos (HQ) foi desenvolvida com personagens em estilo simples, com traços da fisionomia humana não tão ressaltados, a fim de facilitar as expressões dos personagens e interpretações textuais. O roteiro da HQ foi desenvolvido pelos autores, assim como a parte gráfica, pintura, organização dos balões e montagem da revista, em formato PDF. Os traços da HQ foram confeccionados utilizando lápis preto $2 \mathrm{~B}$ e $\mathrm{HB}$ e, após sua finalização, foi necessário contornar as imagens com uma caneta preta hidrocolor, de ponta de $3 \mathrm{~mm}$. Os desenhos foram pintados empregando o software Adobe Photoshop CS5 ${ }^{\mathrm{TM}}$ e os balões com os textos da história criados no software Adobe Illustrator $\mathrm{CS} 5^{\mathrm{TM}}$. A linguagem

Cidadania em Ação: Revista de Extensão e Cultura, Florianópolis (SC), v.4, n.2, jul./dez. 2019. 
adotada nessa HQ propõe uma mistura equilibrada entre ficção e realidade, buscando deixar a leitura mais fluente, prazerosa e atrativa, sem comprometimento da correção dos conceitos científicos envolvidos.

Posteriormente, a HQ foi aplicada em uma atividade de sala de aula, em uma escola pública estadual, para alunos cursando terceiro ano do Ensino Médio, em período noturno, com faixa etária entre 15 e 18 anos, no segundo semestre do ano letivo, com participação ativa e integrada da professora e de estudantes de Licenciatura, no âmbito da disciplina de estágio supervisionado. Para aplicação da HQ na sala de aula, imprimiram-se 10 cópias de cada página, em impressora HP 7710 jato de tinta colorida, as quais foram grampeadas no formato e tamanho de uma revista em quadrinhos. Organizaram-se grupos de 3 alunos e o tempo médio de leitura foi de, aproximadamente, 30 minutos. Ao término da atividade, as HQs impressas foram sorteadas entre os estudantes, a fim de que eles também pudessem divulgá-las para colegas de outras turmas e familiares. Na aula subsequente, realizaram-se discussões sobre os conceitos científicos abordados na HQ, levando os alunos a reflexões sobre os processos químicos e destacando a importância da Química na elucidação de uma investigação criminal e sua relação com a importância de conceitos científicos para a sociedade.

A avaliação da efetividade dessa metodologia de divulgação foi feita por meio de uma abordagem qualitativa, com as observações registradas em diário de campo e gravações de voz. Em tal abordagem, atentou-se para não induzir os alunos a qualquer resposta não espontânea, conforme critérios estabelecidos por Moreira (1985). Com essa metodologia, evita-se a indução de respostas "esperadas", ou questões tendenciosas, que possam prejudicar a obtenção de resultados verídicos. Ao final da atividade com os alunos, também foi feita uma entrevista com a professora, a fim de coletar suas percepções sobre a vivência do uso da HQ em sua prática de ensino e a relação com a divulgação científica.

\section{ELABORAÇÃO DA HISTÓRIA EM QUADRINHOS}

O tema proposto na HQ visava a divulgar, principalmente, a importância da Química para a ciência forense e sua relação com as observações experimentais das reações químicas. A história se passa em uma delegacia de polícia federal, no laboratório de Química Forense. Os personagens são um químico forense, um técnico e uma estagiária e a trama evolui para a investigação de um possível incêndio criminoso, que ocorrera em uma galeria de arte.

Uma vez elaborado todo o roteiro, deu-se início à preparação dos personagens e sua

Cidadania em Ação: Revista de Extensão e Cultura, Florianópolis (SC), v.4, n.2, jul./dez. 2019. 
inserção nos quadrinhos. Primeiramente, eles foram desenhados em folhas sulfite A4, com lápis $2 \mathrm{~B}$ e $\mathrm{HB}$, e depois contornado com caneta preta de ponta $3 \mathrm{~mm}$ (Figura 1).

Figura 1: Desenho da HQ em papel sulfite A4, antes da digitalização e tratamento das cores.

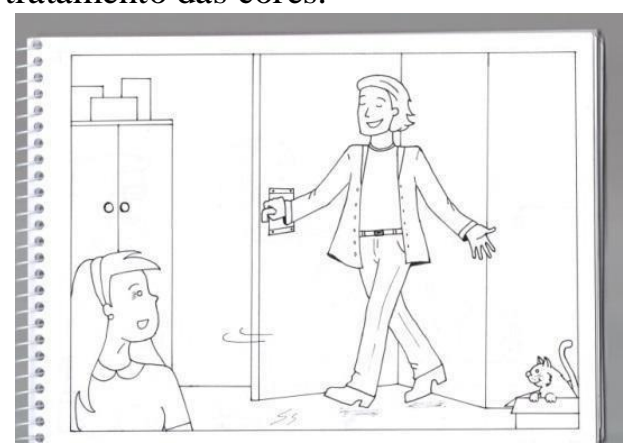

Fonte: Autor

Após a digitalização das imagens em um scanner, elas foram tratadas e pintadas, empregando o software Adobe Photoshop ${ }^{\mathrm{TM}}$ (Figura 2).

Figura 2: Tratamento e ilustração dos desenhos realizados em papel.

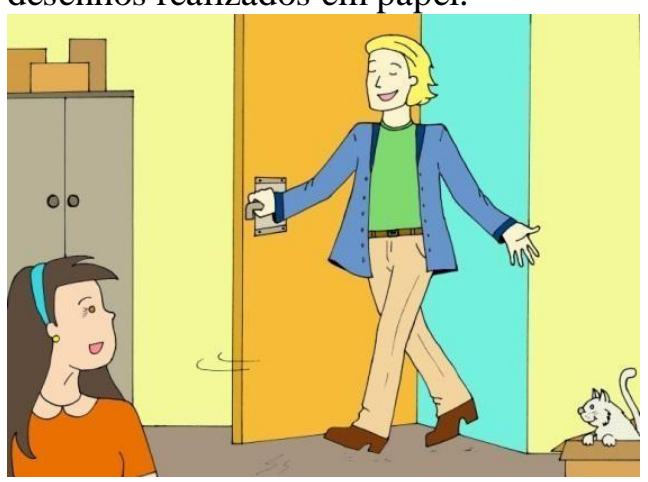

Fonte: Autor

Para montagem dos quadrinhos, utilizou-se o software Adobe Illustrator $^{\mathrm{TM}}$, no acabamento e produção gráfica da edição da HQ (Figura 3). 
Figura 3: A página 11 da $\mathrm{HQ}$, mostrando a arte final das ilustrações, após todo o tratamento digital

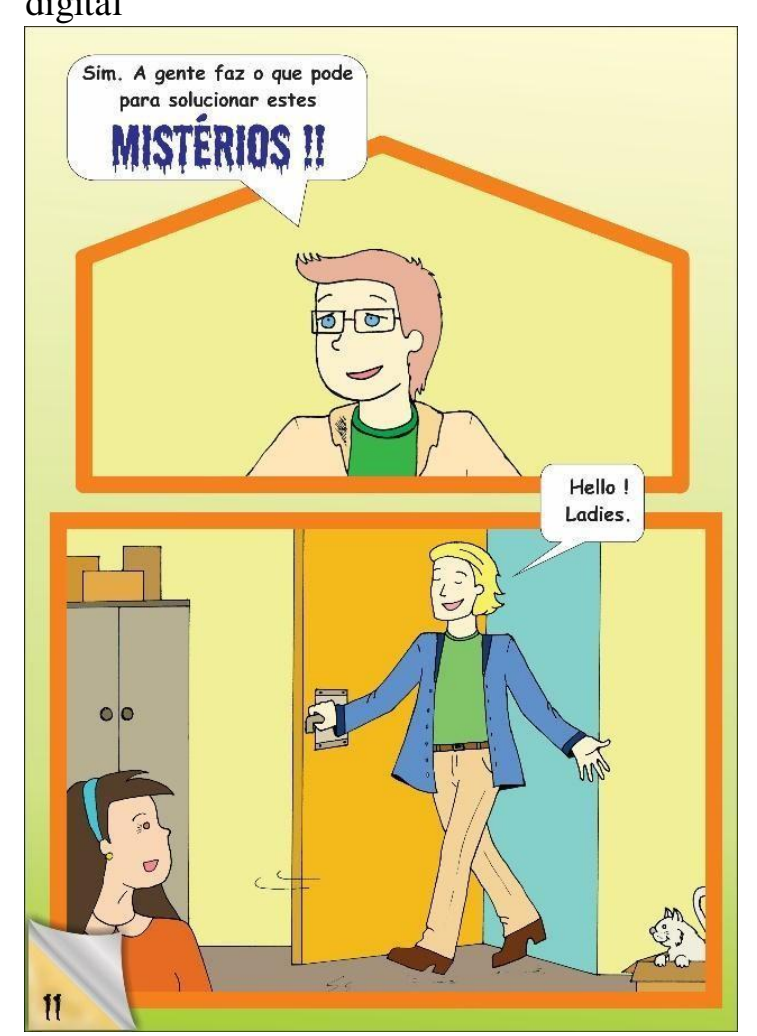

Fonte:Autor

\section{APLICAÇÃO DA HISTÓRIA EM QUADRINHOS EM SALA DE AULA}

Previamente à aplicação da HQ, os estudantes de licenciatura, no âmbito da disciplina de estágio supervisionado, foram à escola para mostrar a HQ e planejar, juntamente com a professora da disciplina, a melhor maneira de aplicá-la em uma atividade de sala de aula. Dessa forma, o presente trabalho também teve por objetivo contribuir na formação inicial e continuada de professores de Licenciatura. Ficou acertado que a melhor opção seria a apresentação e leitura da HQ em uma aula e as discussões na aula subsequente. Houve participação de 76 alunos, em duas salas de terceiro ano do Ensino Médio. Para levantamento dos dados da pesquisa, optou-se por uma análise qualitativa, de acordo com Marconi e Lakatos (2010), avaliando e interpretando, de maneira detalhada, os aspectos e complexidades do comportamento dos alunos:

(...) é o que se desenvolve numa situação natural; é rico em dados descritivos, tem um plano aberto e flexível e focaliza a realidade de forma complexa e contextualizada. Marconi e Lakatos (2010, p. 269). 
As observações qualitativas foram registradas em diário de campo e também gravadas em áudio. Utilizou-se a terminologia EM para representar cada aluno, sendo $\mathrm{N}=$ $1,2, \ldots, 76$. Para os registros das respostas, empregou-se a proposta de Creswell (2010, p. 214), envolvendo questões não estruturadas e, em geral, abertas, em pequeno número e destinadas a suscitar as reais concepções e opiniões dos participantes.

\section{ANÁLISE DOS RESULTADOS}

A presente metodologia abordou aspectos investigativos, formativos e avaliativos, de modo que a pesquisa de campo, com característica qualitativa, foi adaptada, conforme procedimento proposto por Gil (2002), a fim de captar as explicações e interpretações dos alunos, bem como orientar as discussões em grupo, após a aplicação da HQ.

Para analisar os debates e discursos dos alunos, juntamente com a professora da disciplina, nos momentos das discussões tomou-se por base a metodologia proposta por Lefèvre (2003), concentrando-se em apurar as relações coletivas, por meio de dados levantados individualmente, utilizando junções das partes dos depoimentos, ideias centrais e discussões dos conceitos científicos abordados com os alunos.

Para análise dos dados obtidos nessa pesquisa, com abordagem qualitativa, empregaram-se recomendações de Bogdam e Biken (2000), na visão dos quais, geralmente, o estudo de caso é conduzido por um pequeno número de indivíduos, o que facilita as investigações a partir de observações mais direcionadas ao objetivo da proposta. Tal investigação qualitativa não é realizada, exclusivamente, com intuito de obter respostas prévias dos entrevistados (com questões específicas ou muito estruturadas), mas prioriza uma melhor compreensão sobre os comportamentos dos indivíduos envolvidos na pesquisa, uma vez que utiliza-se de uma perspectiva mais abrangente para a investigação.

\section{RESULTADOS E DISCUSSÕES}

DISPONIBILIZAÇÃO DA HISTÓRIA EM QUADRINHOS

A HQ foi produzida em dois volumes e disponibilizada, inicialmente, em formato impresso e, posteriormente, na versão online em pdf, disponível nos sítios:

Volume 1: https://www.4shared.com/office/pTqUV3xfee/HQ_Parte_01.html

Volume 2: https://www.4shared.com/office/aS5o1erCfi/HQ_Parte_02.html

Cidadania em Ação: Revista de Extensão e Cultura, Florianópolis (SC), v.4, n.2, jul./dez. 2019. 
A história ilustra fatos relacionados à profissão de um químico forense, em um departamento de polícia, auxiliando as autoridades a desvendar um possível crime. Os personagens principais são o próprio químico forense: John Craine, seu técnico de laboratório: Bob Person, aluno de pós-Doutorado em Química e a estagiária: Emily Stone, uma estudante de graduação. As explicações dos conceitos científicos são feitas de forma indireta, para não comprometer a ludicidade do roteiro, contudo, utiliza-se certo formalismo, a fim de resguardar a correção de termos científicos, bem como suas explicações. Muitas vezes há uma imagem relacionada, que auxilia no entendimento de conteúdos científicos apresentados ao longo da história.

$\mathrm{O}$ roteiro traz momentos de humor à $\mathrm{HQ}$, nas ações e falas dos personagens, utilizando uma linguagem não tão formal para garantir a fluência textual, porém, sem perder de vista as normas da língua culta, que também são importantes para a formação adequada dos jovens em comunicação e expressão, sobretudo nessa era da Internet. Em determinado instante, aparece a figura de um gato em uma caixa, em referência à famosa experiência imaginária do gato de Schrödinger, que pode servir de base para debates sobre as ideias desse famoso cientista, que foram essenciais ao desenvolvimento da Mecânica Quântica e à concepção do elétron como partícula-onda, permitindo resgatar a evolução histórica e conceitos relacionados à Teoria Atômica.

\section{APLICAÇÃO DA HISTÓRIA EM QUADRINHOS}

Previamente, realizaram-se discussões nas salas de aula para divulgar o amplo emprego da Química em análises forenses realizadas por peritos criminais que, em muitos casos, também são químicos, salientando a importância dos profissionais de Química na resolução de crimes. Nessa etapa, destacou-se a importância da Química na sociedade, lembrando que, atualmente, diversas séries televisivas ilustram a importância dos peritos, que trabalham em conjunto com policiais e detetives na elucidação técnica de investigações criminais. Tudo isso envolve procedimentos experimentais, os quais, por sua vez, exigem conhecimentos teóricos, por exemplo, em Química analítica, especialmente nas reações químicas de identificação de substâncias, comprovando a importância dos conhecimentos científicos para a área criminal.

As histórias em quadrinhos (HQs) foram impressas e encadernadas em formato de gibi. Na aula subsequente, organizaram-se trios nas salas de aula e os estudantes leram a história. Um ponto interessante foi que alunos de alguns grupos quiseram interpretar os

Cidadania em Ação: Revista de Extensão e Cultura, Florianópolis (SC), v.4, n.2, jul./dez. 2019. 
personagens, lendo o texto em voz alta para os colegas, brincando de simular um teatro ou ambiente de contador de histórias. Tal atitude torna evidente o estímulo relacionado ao caráter lúdico da proposta metodológica, gerando um ambiente de descontração entre os alunos e um espaço fértil para o docente estreitar os laços em sua práxis pedagógica, discutindo conceitos e avaliando possíveis dificuldades de aprendizagem, sobretudo relacionadas à leitura, iniciativa de participação e relações interpessoais, habilidades fundamentais à plena formação cidadã, mas que só podem ser trabalhadas, adequadamente, em um sistema de aprendizagem não formal. Segundo Moyles (2002), é importante o uso de estratégias diversificadas na aprendizagem:

Devemos oferecer uma variedade de situações e inovações dentro da sala de aula, que permitam diferentes oportunidades para diferentes crianças e, mais importante, temos de assegurar que cada criança tenha oportunidade de explorar adequadamente um novo meio ou situação e isso significa tentar explorar as experiências com palavras, assim como por meio do brincar. (MOYLES, 2002, p. 57).

Atividades lúdicas promovidas em ambiente escolar representam uma ferramenta pedagógica promissora ao processo de ensino e aprendizagem, com excelentes resultados no Ensino de Ciências e em sua divulgação, abordando todas as fases de aprendizagem escolar. As práticas pedagógicas lúdicas também são indicadas e empregadas no ambiente escolar para oferecer aos alunos uma metodologia que propicie a interação e integração social, práticas relacionadas ao raciocínio lógico e às escolhas e tomadas de decisão, ilustrando que a Ciência está presente em diversos aspectos do seu cotidiano.

Segundo Vygotsky $(1989,2007)$, com relação à teoria sobre o desenvolvimento cognitivo do indivíduo, os alunos têm facilidade na aprendizagem quando os meios educacionais ajudam-no a pensar sobre a situação-problema, contribuindo dessa forma para suas possíveis resoluções. Ainda segundo esse autor, é por meio das interações e atividades executadas, as quais envolvem o uso de simbologias, que o aluno passa a aprender a agir de uma maneira mais cognitiva, incentivando o trabalho em equipe e aproximando-se do docente, propiciando, assim, um melhor desenvolvimento das suas habilidades, como exemplo o raciocínio e facilitando, dessa forma, o processo de aprendizagem dos conceitos científicos propostos nas discussões. 


\section{ANÁLISE DOS RESULTADOS}

A partir das análises do diário de campo, verificou-se ter havido ótima aceitação da história em quadrinhos pelos alunos do Ensino Médio, sendo que a maioria avaliou a proposta como "boa" ou "muito boa" (Tabela 1), corroborando as observações de Francisco Júnior e Gama (2017):

A aceitação dos estudantes pela história em quadrinhos esteve provavelmente balizada pela atratividade deste material em função de sua ludicidade e o "modo diferente" de abordar conceitos químicos. (Francisco Júnior e Gama, 2017, p. 170).

Tabela 1: Avaliação da história em quadrinhos pelos alunos de Ensino Médio

\section{Conceito}

Porcentagem (\%)

\begin{tabular}{lc}
\hline 1 a 2 (muito ruim) & 2 \\
3 a 4 (ruim) & 4 \\
5 a 6 (razoável) & 8 \\
7 a 8 (boa) & 24 \\
9 a 10 (muito boa) & 62
\end{tabular}

Fonte: Elaborado pelo autor.

Por meio das análises das transcrições dos diálogos vivenciados durante a aplicação da HQ na sala de aula, verificou-se que a novidade metodológica foi ponto importante para a promoção do interesse dos alunos pela atividade. Os diálogos transcritos a seguir confirmam tal observação:

\footnotetext{
“... pensar a Química em um quadrinho é bem diferente.” Aluno AAV

“... podemos participar em grupo; desse jeito, fica mais legal a aula." Aluna GJJ

“... uma maneira interessante de mostrar meu dom de dublador. Mas nunca imaginaria sobre esta disciplina.” Aluno PDMR
}

Aos alunos que relataram como interessante o uso da HQ aplicado a divulgação científica, destacamos que a função motivadora e a lúdica são pontos cruciais para o sucesso da proposta metodológica. Diversos pesquisadores têm demonstrado que o uso de HQs em sala de aula é um fator preponderante enquanto ferramenta para melhorar o processo de interesse aos conteúdos mais abstratos, em especial de Química (FRANCISCO JÚNIOR; GAMA, 2017; IWATA; LUPETTI, 2017; IANESKO et al., 2017; FRANCISCO JÚNIOR; UCHÔA, 2015; KAWAMOTO; CAMPOS, 2014). Segundo Chateau (1987) as atividades lúdicas possuem uma relação muito forte com um desafio a ser superado na proposta, um estímulo a ser quebrado, ou desvendado, fazendo com que o aluno passe a se dedicar mais

Cidadania em Ação: Revista de Extensão e Cultura, Florianópolis (SC), v.4, n.2, jul./dez. 2019. 
intensamente para atingir o objetivo.

A Tabela 2 demonstra a percepção do interesse e da motivação dos alunos que participaram dessa vivência do emprego da HQ como ferramenta para o interesse pela Ciência.

Tabela 2: Aspectos positivos mencionados pelos alunos durante a aplicação da atividade, com base nas observações comportamentais levantadas na abordagem qualitativa.

\begin{tabular}{lc}
\hline \multicolumn{1}{c}{ Aspecto positivo } & Resultados positivos (\%) \\
\hline A HQ ajudou na compreensão das discussões sobre reações & 68 \\
químicas. & 100 \\
Foi possível observar a contextualização da Química e a & \\
sociedade. & 100 \\
A HQ ajudou a perceber o uso da Química para fins & 88 \\
investigativos. & \\
A HQ trouxe um conhecimento que eu desconhecia em & 96 \\
Ciência. & 92 \\
Como divulgação, a proposta poderia ser utilizada para \\
meus colegas de outras turmas. \\
A proposta é interessante e atrativa
\end{tabular}

Fonte: Elaborada pelo autor.

Analisando a Tabela 2, verifica-se que a maioria dos alunos acredita que a atividade foi importante e significativa para contextualizar, divulgar e discutir conceitos de Química em sala de aula. Alguns comentários registrados em diário de campo e transcritos a seguir corroboram os resultados apresentados na Tabela 2.

"É importante que sempre tenham essas atividades diferentes em sala de aula, assim não fica chato e acabamos conhecendo mais sobre o assunto." Aluna BBT

“... no início não estava gostando da proposta, mas, com a leitura e as situações entre os policiais e a Química, foi ficando muito mais legal. Agora posso avaliar bem melhor isso aqui." Aluna AMQ

Um fato importante a ser salientado foi a grande e ativa participação dos alunos durante a execução da proposta. Nas aulas tradicionais, conforme relato da professora registrado em diário de campo, diversos alunos apresentavam comportamento bem passivo, não questionavam e não eram participativos nas discussões dos assuntos de Ciências. Durante a atividade da HQ, ela observou que muitos desses alunos participaram

Cidadania em Ação: Revista de Extensão e Cultura, Florianópolis (SC), v.4, n.2, jul./dez. 2019. 
intensamente da aula e relatou ter vivenciado discussões entre alunos que nunca haviam questionado nada em aula antes; a atividade com a HQ induziu esses alunos a saírem de sua zona de conforto e interagir com o tema e com os demais colegas. Alguns desses alunos, inclusive, fizeram questão de ler os quadrinhos para os colegas, representando os personagens de maneira cômica. Segundo Ianesko, a HQ ajuda a criar um contexto próprio de divulgação, ensino e aprendizagem:

Pode-se observar que a utilização dos quadrinhos despertou um maior interesse nos alunos, possivelmente porque estão acostumados com as aulas tradicionais. Quando surge algo novo a ser desenvolvido, distinto do que costumam observar em sala, desperta-se maior interesse, motivando o desenvolvimento de sua própria história sobre o conteúdo, tornando-se, assim, um aluno mais participativo. (IANESKO et al., 2017, p. $115)$.

Santos et al. (2012) apontam que uma dificuldade para uso das HQs na área da Ensino é o fato de tal publicação ser voltada, principalmente, ao entretenimento dos leitores, desprovida de relação acadêmica com o conhecimento científico e constituindo, assim, mais uma forma de mídia de comunicação em massa. Nessa perspectiva, é necessário que tal quadro seja revertido e também porque, segundo os PCN, o emprego das HQs é recomendado somente no ensino de Língua Portuguesa, não havendo incentivo para que elas sejam utilizadas em outras áreas do conhecimento.

Pela análise do diário de campo, constatamos que o uso das HQs como processo metodológico de divulgação científica pode ser realizado para diversas aplicações e finalidades didáticas, como na divulgação científica de áreas pouco conhecidas pela população, apresentando facilidade de transposição do texto para a dramaturgia, na discussão de conteúdos científicos descritos em enredos históricos, para melhorar a relação acadêmica entre os alunos e deles com o professor, devido à integração em sala de aula que a atividade lúdica propicia. Destaca-se também o fato de que o uso das HQs pode contribuir para que os alunos ampliem sua prática da leitura, gerando incentivo e despertando motivação para outros tipos de leitura, como revistas, livros ou jornais, promovendo-lhes uma aprendizagem bem mais significativa e diversificada dos assuntos científicos e suas correlações com o cotidiano.

As HQs fazem parte das tecnologias da informação e comunicação (TIC) e, no presente trabalho, ficou evidente que os alunos passaram a atuar como protagonistas de sua própria aprendizagem e reforçando o interesse pela Ciência. O público em geral é atraído pela leitura de quadrinhos (SOARES; CRUZ, 2016), independente da forma, podendo ser uma tirinha cômica, uma charge ilustrativa, um mangá etc. Tal ampla aceitação das HQs se

Cidadania em Ação: Revista de Extensão e Cultura, Florianópolis (SC), v.4, n.2, jul./dez. 2019. 
deve ao seu intenso caráter lúdico e, muitas vezes, interdisciplinar, com forte interação com o cotidiano em seus enredos (CAVALCANTE et al., 2015).

\section{CONSIDERAÇÕES FINAIS}

A utilização da HQ para a divulgação científica demonstrou ser uma ferramenta interessante para a apresentação de conceitos científicos, sendo que a inserção de situações do cotidiano no ambiente escolar constitui-se elemento motivador de aprendizagem. No presente trabalho, a aceitação demonstrada pelos alunos na utilização da HQ em uma atividade de Química em sala de aula foi excelente, independentemente do comportamento prévio dos estudantes em relação às aulas tradicionais. Além disso, o emprego de atividades não tradicionais têm demonstrado que outras habilidades e competências podem ser melhor trabalhadas em sala de aula, contribuindo para uma maior integração entre os alunos e para que o docente possa realizar uma práxis pedagógica mais próxima dos educandos, ampliando o interesse pela disciplina e contribuindo, dessa forma, para uma aprendizagem mais significativa e motivadora. As atividades desenvolvidas no presente trabalho também contribuíram para a formação inicial de estudantes de licenciatura, que participaram ativamente da aplicação da HQ em sala de aula, bem como para a formação continuada da professora, que nunca havia vivenciado uma atividade lúdica em suas aulas. 


\section{REFERÊNCIAS}

ALMEIDA, L. T. G.; AYALA, J. D.; QUADROS, A. L. As videoaulas em foco: que contribuições podem oferecer para a aprendizagem de ligações químicas de estudantes na educação básica? Química Nova na Escola, [s.1], v. 40, n. 4, p. 287-296, 2018.

BOGDAN, R.; BIKLEN, S. Investigação qualitativa em educação. Porto: Porto Editora, 2000.

CABELLO, K. A. S.; ROCQUE, L. L.; SOUZA, I. C. F. Uma história em quadrinhos para o ensino e divulgação da hanseníase. Revista Electrónica de Enseñanza de las Ciencias, [s.1], v. 9, n. 1, p. 225-241, 2010.

CALAZANS, F. M. A. História em quadrinhos na escola. São Paulo: Editora Paulus, 2004.

CAVALCANTE, K. S. B.; SILVA, F. C.; MACIEL, A. P.; LIMA JUNIOR, J. A. S.;

RIBEIRO, J. S. S.; SANTOS, P. J. C.; PINHEIRO, A. E. P. Educação ambiental em histórias em quadrinhos: recurso didático para o ensino de ciências. Química Nova na Escola, [s.1] v. 37, n. 4, p. 270-277, 2015.

CHATEAU, J. O jogo e a criança. São Paulo: Summus, 1987.

CRESWELL, J. W. Projeto de pesquisa: métodos qualitativo, quantitativo e misto. $3^{\text {a }}$ ed., Porto Alegre: Artmed, 2010.

FRANCISCO JÚNIOR, W. E.; UCHÔA, A. M. Desenvolvimento e avaliação de uma história em quadrinhos: uma análise do modo de leitura dos estudantes. Educación Química, [s.1], v. 26, n. 2, p. 87-93, 2015.

FRANCISCO JÚNIOR, W. E.; GAMA, E. J. S. História em quadrinhos para o ensino de química: contribuições a partir da leitura de licenciandos. Revista Electrónica de Enseñanza de las Ciencias, [s.1], v. 16, n. 1, p. 152-172, 2017.

GIL, A. C. Como elaborar projetos de pesquisa. 4. ed. São Paulo: Atlas, 2002.

GIRON, L. A. A dublagem venceu as legendas. Revista Época. Ed. Globo. v. 6, n. 6, p. 3233, 2012.

IANESKO, F.; ANDRADE, C. K.; FELSNER, M. L.; ZATTA, L. Elaboração e aplicação de histórias em quadrinhos no ensino de ciências. Experiências em Ensino de Ciências, [s.1], v. 12, n. 5, p. 105-125, 2017.

IWATA, A. Y.; LUPETTI, K. O. Histórias de vidro em quadrinhos: o ensino e a divulgação científica de conceitos sobre o vidro. Revista eletrônica Ludus Scientiar, [s.1], v. 1, n. 1, p. 75-92, 2017. 
KAWAMOTO, E. M.; CAMPOS, L. M. L. Histórias em quadrinhos como recurso didático para o ensino do corpo humano em anos iniciais do ensino fundamental. Ciências \& Educação, [s.1], v. 20, n. 1, p. 147-158, 2014.

LEFÈVRE, F. Discurso do Sujeito Coletivo: um novo enfoque em pesquisa qualitativa. Caxias do Sul: EDUCS, 2003.

MARCONI, M. A.; LAKATOS, E. M. Fundamentos de metodologia científica. 7.ed. São Paulo: Atlas, 2010.

MOREIRA, M. A. \& KROFF, E. D. O questionário como instrumento de coleta de informações sobre o ensino. In: Moreira, M. A. (org). Ensino na universidade: sugestões para o professor. Porto Alegre: Editora da Universidade, 1985.

MOYLES, J. R. Só brincar? O papel do brincar na educação infantil. Porto Alegre: Artmed, 2002.

NETO, H. S. M.; PINHEIRO, B. C. S.; ROQUE, N. F. Improvisações teatrais no ensino de química: interface entre teatro e ciência na sala de aula. Química Nova na Escola, [s.l], v. 35 , n. 2, p. 100-106, 2013.

OLIVEIRA, A. L.; OLIVEIRA, J. C. P.; NASSER, M. J. S.; CAVALCANTE, M. P. O jogo educativo como recurso interdisciplinar no ensino de química. Química Nova na Escola, [s.1], v. 40, n. 2, p. 89-96, 2018.

PIZARRO, M. V. As histórias em quadrinhos como linguagem e recurso didático no ensino de ciências. In: ENCONTRO NACIONAL DE PESQUISADORES EM EDUCAÇÃO EM CIÊNCIAS, 7., 2009.

SANTOS, V. J. R. M.; SILVA, F. B.; ACIOLI, M. F. Produção de histórias em quadrinhos na abordagem interdisciplinar de biologia e química. Renote, [s.1], v. 10, n. 3, p. 1-8, 2012.

SANTOS, R. E. A história em quadrinhos na sala de aula. INTERCOM - Sociedade Brasileira de Estudos Interdisciplinares da Comunicação. In: CONGRESSO BRASILEIRO DE CIÊNCIAS DA COMUNICAÇÃO, 26., 2003, Belo Horizonte: UFMG.

SILVA, M. P.; KIOURANIS, N. M. M. A música e o ensino de química. Química Nova na Escola, [s.1], v. 28, n. 1, p. 28-31, 2008.

SILVA, J. L.; SILVA, D. A.; MARTINI, C.; DOMINGOS, D. C. A.; LEAL, P. G.;

BENEDETTI-FILHO, E.; FIORUCCI, A. R. A utilização de vídeos didáticos nas aulas de química do ensino médio para abordagem histórica e contextualizada no tema vidros. Química Nova na Escola, [s.1], v. 34, n. 4, p. 189-200, 2012.

SOARES, M. H. F. B.; CRUZ, T. M. G. S. H'química: o uso dos quadrinhos para o ensino de radioatividade. Temporis(ação), [s.1], v. 16, n. 2, p. 289-307, 2016. 
TESTONI, L. A. \& ABID, M. L. V. S. A utilização de histórias em quadrinho no ensino de física. In: ENCONTRO NACIONAL DE PESQUISA EM EDUCAÇÃO EM CIÊNCIAS, 10., 2003, São Paulo. Anais.

VERGUEIRO, W. C. S. As histórias em 10 quadrinhos. Folha de São Paulo, São Paulo, 2004.

VERGUEIRO, W. C. S.; RAMA, Â. Como usar as histórias em quadrinhos em sala de aula. São Paulo: Contexto, 2004.

VILLELA, G. C.; OLIVEIRA, S. \& LAUDARES, F. A. L. Histórias em quadrinhos para o ensino de física: um método simples de construção. In: CONGRESSO NACIONAL DE EDUCAÇÃO, 8., 2017, Curitiba. Anais.

VYGOTSKY, L. S. A formação social da mente. In: Interação entre aprendizado e desenvolvimento. $7^{\circ}$ ed., São Paulo: Martins Fontes, 2007.

, L. S. A formação social da mente: o desenvolvimento dos processos psicológicos superiores. São Paulo: Martins Fontes, 1989. 